\title{
The Male Attitude Norms Inventory-II
}

\author{
A Measure of Masculinity Ideology in South Africa
}

\author{
RUSSELL LUYT \\ University of Cape Town
}

\begin{abstract}
This article describes the development of the Male Attitude Norms Inventory-II (MANI- II). Empirical findings and theoretical debate contributed toward the development of a measure of South African masculinity ideology. Three hundred and thirty-nine male par- ticipants, drawn from universities across greater Cape Town, were included in the study. Exploratory factor analysis rendered a three-factor model of traditional masculinity. This accounted for 31.44 percent of total item variance. Results informed the develop- ment of a Total Scale ( $=0.90$ ) as well as three subscale measures (Toughness, $=0.81$; Control, $=0.82$; and Sexuality, =0.85). The MANI-II displayed satisfactory conver- gent validity with the Male Role Norms Inventory (MRNI) ( $\mathrm{r}=$ 0.84; $\mathrm{p}<0.001$ ). The MANI-II and MRNI subscales were also meaningfully interrelated. The MANI-II offers a contextually sensitive and multidimensional measure of masculinities. Future research should include a representative sample, establish test-retest reliability, and further examine total and subscale construct validity.
\end{abstract}

Key words: South Africa; masculinities; masculinity ideology; measurement

Author's Note: This article draws on research undertaken under the auspices of the Department of Psychology at the University of Cape Town. Research funds were made partially available through the university. Particular thanks go to Ronald Levant for making his work accessible, Jenny Luyt for her unreserved encouragement, and Don Foster for his overall supervisory guid- ance and support. Correspondence should be sent to the London School of Economics, Depart- ment of Social Psychology, Houghton Street, London WC2A 2AE, United Kingdom.

Men and Masculinities, Vol. 8 No. 2, October 2005 208-229

DOI: $10.1177 / 1097184 X 04264631$

This article describes the development of the Male Attitude Norms Inventory-II (MANI-II) through the revision of its predecessor the Male Attitude Norm Inventory (MANI) (Luyt and Foster 2001). The MANI was first devised and applied in research seeking to investigate hegemonic mas- culine conceptualization in South African gang culture. However, Luyt and Foster (2001) argue that the MANI lacks validity within South Africa'smulticultural society because of a conceptual overreliance on existing West- ern measures of masculinity(ies). A number of criteria are considered vital in the development of gender mea- sures (Beere 1990). At a minimum, it is believed that all instruments should (1) find root in empirical evidence and/or theoretical reasoning, (2) exhibit con- struct validity, and (3) demonstrate substantive reliability. Each of these three criteria, as they apply to the revision of the MANI-II, is discussed below. 


\section{Measuring Masculinity(ies)}

Thompson, Pleck, and Ferrera (1992) propose a useful conceptual framework for understanding the intrinsic differences that exist between measures of masculinity(ies). Although this explanation has met with some criticism (Thompson and Pleck 1995), it proves useful in describing the perspective adopted in this article. In short, it is argued that instruments of masculine measurement fall into one of two independent categories: those seeking to measure gender orientation or others attempting to explore gender ideology (Thompson, Pleck, and Ferrera 1992; Thompson and Pleck 1995). Readers are advised to consult Thompson, Pleck, and Ferrera (1992) as well as Thompson and Pleck (1995) for a comprehensive discussion surrounding this distinction.

Gender orientation. Gender orientation assumes that actual personality differences underlie gender. These are deemed measurable through the precise definition and empirical study of invariant personality traits. Sex role theorizing best reflects this "trait perspective," where gender is understood as either psychologically or biologically innate. Masculinity and femininity are crucially argued to exist as unidimensional and interdependent constructs (Levant 1996; Thompson, Pleck, and Ferrera 1992; Thompson \& Pleck, 1995). Archer (1989) notes the popular emergence of gender trait measures during the early 1970s. In particular, the Bem Sex Role Inventory (Bem 1974) and the Personal Attributes Questionnaire (Spence, Helmreich, and Stapp, 1974) found prolific use during this period (Beere 1990).

Early trait measures stressed the interdependence of sex roles in which masculinity and femininity were seen to exist on opposite ends of a gender continuum (Beere 1990; Lenney 1991). At worst, this implied the mentally maladaptive nature of inappropriate individual sex typing. Nevertheless, later theorizing recognized the independence of gender constructs. This not only questioned whether "appropriate" sex typing was crucial to mental health but also stressed the developmentally restrictive nature of traditional roles (Lenney 1991).

Notwithstanding these progressive shifts, measures finding raison d'être within gender orientation continue to suffer from fundamental weaknesses; 
these are highlighted in critiques of sex role theory (see Brittan 1989; Connell 1987; Wetherell and Griffin 1991). Most important, it is argued that these explanations fail to capture contextual fluidity in gender definition through their emphasis on universal and homogeneous gender categories. Such an apolitical outlook effectively ignores the effect that uneven power relations have in both compliance to and endorsement of traditional gender roles (Thompson, Pleck, and Ferrera 1992). Furthermore, Lenney (1991) notes that despite their popular use, concepts such as masculinity and femininity have remained ill defined to the extent that instruments purporting to evaluate sex roles regularly fail to measure the same construct. In their pursuit of a "true" masculinity and femininity, trait measures lack recognition that they find production within a unique cultural and historical environment and, as such, fail to appreciate "that 'masculinity' and 'femininity' are what is measured by masculinity and femininity scales” (Beere 1990, 32).

Gender ideology. Alternatively, gender ideology advocates the importance of socially constructed gender norms. This "normative perspective" situates gender as a sociocultural artifact rather than a psychological or biological fact. Measures are designed to "index the extent to which individuals endorse the ideas and beliefs that serve to justify gender scripts and power relations" (Thompson, Pleck, and Ferrera 1992, 576). These measures crucially stress the independence and multidimensionality of masculinity and femininity constructs.

An emphasis on construct multidimensionality recognizes variability in gender conceptualization. This is seen as an unavoidable consequence of, among other things, an individual's location within shifting power relations (Archer 1989; Levant 1996; Thompson and Pleck 1995). Moreover, construct independence suggests that masculinity and femininity do not rely on strict binary definition. This enables seemingly contradictory ideologies to emerge that are unhampered by rigid co-definitions surrounding what it is to be a traditional man vis-à-vis a traditional woman. For instance, a man may endorse progressive views surrounding male involvement in childcare but still support established notions concerning female domestic responsibility. Thompson, Pleck, and Ferrera (1992) note that firm evidence for construct independence exists in that masculinity and femininity exhibit different correlates.

Among some of the most notable attempts to operationalize masculinity ideology are the Brannon Masculinity Scale (BMS) (Brannon and Juni 1984), the Male Role Norms Scale (MRNS) (Thompson and Pleck 1986, 1987), and the Male Role Norms Inventory (MRNI) (Levant et al. 1992). Likewise, the MANI was implicitly devised under the theoretical aegis of gender ideology. This is illustrated by the prominence of social constructionist thought, as well as the conceptual role played by two existing measures of masculine ideology, during its derivation (Luyt and Foster 2001). 


\section{METHOD}

\section{Sample}

In total, 339 questionnaires were completed by male undergraduate and graduate students from Stellenbosch University, the University of Cape Town, and the University of the Western Cape. This represented a high response rate of 89.92 percent. As a consequence of institutionalized discrimination during Apartheid, Stellenbosch University and the University of Cape Town have historically catered to the needs of the white minority. The former continues instruction predominantly in Afrikaans, while the latter does so largely in English. Similarly, the University of the Western Cape continues to reflect a segregationalist past, primarily consisting of members from previously disadvantaged groups including so-called "blacks," "coloreds," and "Asians." Xhosa-speaking participants were more easily recruited at this institution. Although the racial composition of these institutions has and is changing rapidly, they nevertheless provided a useful way through which to access different population groups.

Participant age ranged between 17 and 38 and averaged 20.75 years. The majority (95.8 percent) were unmarried and were enrolled in a humanitiesrelated course (46 percent). "Race" representation was markedly skewed in which the bulk of all respondents classified themselves as "white" (46.02 percent). Although such categorization holds unpalatable political implications, perhaps demonstrated by the 13.76 percent of participants who failed to identify their "race" as a possible means of protest, such information provided a suitable proxy measure of ethnicity.

The sample should not be seen as representative of the male South African population. Participants originated from a privileged educational background, predominantly undertook study within a humanities field, and unevenly represented the views of a young, "white," ethnic minority. The results should be understood from within these limitations.

\section{The Male Attitude Norms Inventory-II}

As noted above, the MANI-II (see appendix) emerged through the revision of the MANI (Luyt and Foster 2001). The MANI took form around two existing instruments: the Male Role Norms Inventory (MRNI) (Levant et al. 1992) and the Male Role Norms Scales (MRNS) (Thompson and Pleck 1986, 1987). Both these instruments have been classified as measures of masculinity ideology (Thompson and Pleck 1995). Relevant gender literature also aided in the design of a conceptual model of traditional masculinity. This incorporated five core dimensions. Four interrelated second-order constructs appeared under each of these (see Table 1). (Readers are encouraged to 
Table 1:

Five Theoretically Motivated Dimensions Included within the Male Attitude Norm Inventory and Their Underlying Constructs

\begin{tabular}{|c|c|c|c|c|}
\hline Antifemininity & Toughness & Individualism & Status & Homophobia \\
\hline $\begin{array}{l}\text { Female sexual } \\
\text { objectification }\end{array}$ & $\begin{array}{r}\text { Discomfort } \\
\text { tolerance }\end{array}$ & $\begin{array}{l}\text { Assertive } \\
\text { activity }\end{array}$ & $\begin{array}{l}\text { Achievement } \\
\text { management }\end{array}$ & $\begin{array}{c}\text { Homophobic } \\
\text { ostracism }\end{array}$ \\
\hline $\begin{array}{c}\text { Antifeminine } \\
\text { practice }\end{array}$ & $\begin{array}{l}\text { Emotional } \\
\text { detachment }\end{array}$ & $\begin{array}{l}\text { Level-headed } \\
\text { practice }\end{array}$ & $\begin{array}{l}\text { Career } \\
\text { management }\end{array}$ & $\begin{array}{c}\text { Homophobic } \\
\text { violence }\end{array}$ \\
\hline $\begin{array}{c}\text { Male sexual } \\
\text { prowess }\end{array}$ & Self-containment & $\begin{array}{l}\text { Male } \\
\text { independence }\end{array}$ & $\begin{array}{l}\text { Resource } \\
\text { management }\end{array}$ & $\begin{array}{l}\text { Antihomoerotic } \\
\text { practice }\end{array}$ \\
\hline $\begin{array}{l}\text { Female } \\
\text { belittlement }\end{array}$ & $\begin{array}{l}\text { Physical } \\
\text { practice }\end{array}$ & $\begin{array}{l}\text { Interpersonal } \\
\text { dominance }\end{array}$ & $\begin{array}{l}\text { Power } \\
\text { management }\end{array}$ & $\begin{array}{l}\text { Heterosexual } \\
\text { self-regulation }\end{array}$ \\
\hline
\end{tabular}

contact the author for further details surrounding construct operational definitions.) This conceptual model found operationalization through item development, in some cases drawing on those included within the MRNI and the MRNS, although these often underwent slight alteration to make them more suitable to the cultural and linguistic flavor of the South African population.

The complete measure encompasses the use of forty belief statements that reflect dominant notions of masculinity. Participants are asked to indicate along a five-point response format whether they strongly disagree, disagree, have no opinion, agree, or strongly agree with these male oriented items. A high item score is argued to signal an individual's agreement with traditional conceptualizations of masculinity.

Three theoretically congruent factors emerged through the use of factor analytic techniques: Toughness ( $=0.82)$, Success $(=0.46)$, and Control ( = 0.78). Toughness and success ideologies appeared in like form within both the MRNI and the MRNS. However, control ideology was notably absent as a single dimension from these preexisting instruments. Luyt and Foster (2001) tentatively suggest that the centrality-afforded notions of male control within the MANI better summarize the array of alternative dimensions, other than toughness and success, propagated by these older measures. Notably, the 26 percent of total item variance accounted for by the three 
extracted factors appeared in close approximation to the 28 percent total item variance explained by the similar factorial study conducted by Thompson and Pleck (1987) using the MRNS.

Ultimately, the MANI fails to generate a comprehensive contextual understanding of masculinity. That is to say, little new knowledge concerning a participant's masculine conceptualization, apart from an amalgamation of traditionally recognized elements of dominant masculinity, finds original production. This suggested the need to conduct further in-depth exploration of contextual masculine understanding as opposed to simply applying an a priori model of traditional masculinity.

The development of the MANI-II may be seen as an attempt to improve the MANI through both empirical and theoretical means. That is to say, the revision of the MANI through a thorough qualitative exploration of masculinities in South Africa and an examination of existing factor analytic results, in accordance with the assumptions of gender ideology, were considered beneficial.

EMPIRICAL REVISION OF THE

MALE ATTITUDE NORM INVENTORY

The empirical revision of the MANI made use of qualitative and quantitative data. Qualitative exploration into masculinities provided valuable insight as to their unique and variable conceptualization in South Africa (Luyt 2003). The following seven key metaphorical dimensions of traditional masculinity emerged: (1) control, (2) (un)emotionality, (3) physicality and toughness, (4) success, (5) competition, 6) responsibility, and (7) (hetero)sexuality.

These dimensions all arguably found account in the original conceptual model of the MANI. This provided firm evidence in favor of the instruments content validity. However, it was clear that item content neglected issues of sexuality in masculine definition. That is to say, although the MANI included a dimension of homophobia, it was felt that this did not adequately encompass the notion of performative sexuality, which continually emerged as a powerful metaphor in participant discussion. Both the MANI (i.e., eight out of forty items) and the MRNI (i.e., twelve out of fifty-seven items) were explicitly formulated to include sexuality-related items (Thompson \& Pleck 1995). Yet despite their accounting for the importance of sexuality, it was believed that this required even further emphasis, achieved through the inclusion of the two conceptually distinct dimensions of sexuality and homophobia within the MANI-II (see Table 2). This emphasis extended the revised instrument's investment in sexuality-related items to sixteen out of forty.

The distinction between these two dimensions is easily understood. While sexuality attempts to tap masculine sexuality as a performance, consisting of 
Table 2:

Five Revised Dimensions Included within the Male Attitude Norms Inventory-II and Their Underlying Concepts

\begin{tabular}{|c|c|c|c|c|}
\hline Sexuality & Toughness & Individualism & Status & Homophobia \\
\hline $\begin{array}{l}\text { Objectification } \\
\text { of sex }\end{array}$ & $\begin{array}{r}\text { Discomfort } \\
\text { tolerance }\end{array}$ & $\begin{array}{l}\text { Assertive } \\
\text { activity }\end{array}$ & $\begin{array}{l}\text { Achievement } \\
\text { management }\end{array}$ & $\begin{array}{c}\text { Homophobic } \\
\text { ostracism }\end{array}$ \\
\hline Sexual control & $\begin{array}{l}\text { Emotional } \\
\text { detachment }\end{array}$ & $\begin{array}{l}\text { Level-headed } \\
\text { practice }\end{array}$ & $\begin{array}{l}\text { Career } \\
\text { management }\end{array}$ & $\begin{array}{c}\text { Homophobic } \\
\text { violence }\end{array}$ \\
\hline $\begin{array}{l}\text { Sexual } \\
\text { performance }\end{array}$ & Self-containment & $\begin{array}{l}\text { Male } \\
\text { independence }\end{array}$ & $\begin{array}{l}\text { Resource } \\
\text { managem }\end{array}$ & $\begin{array}{l}\text { Antihomoerotic } \\
\text { practice }\end{array}$ \\
\hline $\begin{array}{r}\text { Masculine } \\
\text { practice }\end{array}$ & $\begin{array}{l}\text { Physical } \\
\text { endurance }\end{array}$ & $\begin{array}{l}\text { Interpersonal } \\
\text { dominance }\end{array}$ & $\begin{array}{l}\text { Power } \\
\text { management }\end{array}$ & $\begin{array}{c}\text { Homophobic } \\
\text { avoidance }\end{array}$ \\
\hline
\end{tabular}

various definitive practices (e.g., item 38: "A man should make sure that he knows about sex" [Sexual Control]), homophobia specifically explores notions of other versus dominant sexual expression (e.g., item 21: "It is wrong for a man to be seen in a gay bar" [Homophobic Avoidance]). The inclusion of the entirely new sexuality dimension within the MANI-II required producing a number of innovative items representing its underlying concepts. For instance, in operationalizing the second-order construct of sexual performance, a statement concerning erectile dysfunction was formulated:

Item 16: Men should feel embarrassed if they are unable to get an erection during sex (MANI-II).

In a general sense, exploration of South African masculinities sensitized the instrument revision to subtle cross-cultural differences in masculine display that rendered particular items inappropriate. This is well illustrated by the following:

Item 39: Men should not wear bracelets (MANI).

In retrospect, this was deemed a poor means through which to operationalize the concept of heterosexual self-regulation, as cross-cultural displays of 
heterosexuality are varied. This militated against the use of such culturally specific (Western) notions of heterosexual behavioral practice in assessing participant endorsement of heterosexuality.

Quantitative data also contributed toward empirical revision of the MANI through the use of findings from previous research (Luyt and Foster 2001). Inventory items that were found to have insubstantive factor loadings $(<0.4)$ during exploratory factor analysis were scrutinized in an attempt to isolate possible explanations. One such item (item 12) read, "Using a gun is sometimes the only way to get out of a bad situation” (MANI).

In this case, item factor loading proved insubstantive. However, it was puzzling that item 11 , similarly assessing the concept of physical endurance, emerged substantive. In hindsight, it was argued that the notion of using a weapon might well have been a poor means of assessing violent physicality because of the absence of explicit bodily action. As such, the revised item in the MANI-II attempted to assess support for the use of physical violence in a direct fashion, as well as accommodating a less extreme attitude towards support for the use of physical violence:

Item 22: Men should be prepared to physically fight their way out of a bad situation (MANI-II).

Notably, this revised item emerged substantive in the present study, providing support for the suggestion that the original item operationalized its underlying concept poorly.

In sum, both qualitative and quantitative methods were used in the revision of the MANI. Qualitative findings suggested the need to include the entirely new dimension of sexuality in addition to the existing but conceptually discreet axis of homophobia in an effort to account for the large role sexuality-related issues were found to play in masculine definition. In retrospect, a number of items were also considered to be culturally insensitive and were altered accordingly. Quantitative data were used to pinpoint potentially problematic items. These were considered and revised where necessary.

THEORETICAL REVISION OF THE

MALE ATTITUDE NORM INVENTORY

Theoretical revision of the MANI began at a basic level. Thompson and Pleck (1995) note that the use of plural has become a popular means with which to express variability in the conceptualization of masculinity and femininity. As such, the MANI underwent a name change to stress the multidimensionality of the masculinity construct. That is to say, the use of plural in the title - the Male Attitude Norms Inventory-II—-is believed to convey the theoretical assertion that masculinities are reflected in multiple norms as opposed to a single masculinity script. 
Additionally Thompson, Pleck, and Ferrera (1992) outline four key principles that either distinguish instruments of masculinity ideology from those measuring other constructs, such as gender orientation, or enhance their utility as tools of ideological measurement:

\& Third-person statements are believed to augment an evaluation of shared normative views, which exist ideologically "out-there," to a greater extent than first-person statements that locate masculinity as an internalized set of values.

\& Comparative gender statements should be avoided, as attitudes held toward men are considered independent from those concerning women, which together might better investigate gender ideology.

\& Instruments should include items reflecting both a traditional and a progressive masculinity ideology.

\& Statements should be prescriptive (i.e., what men "should be like") in their exploration of dominant attitudes, as well as descriptive (i.e., what men "actually are like”) in their appraisal of perceived dominant behavior.

All items within the MANI-II adhere to this guideline. For example, in instances where first-person statements had previously been included within the MANI, these were altered so as to better reflect ideology through the use of the third person:

First person: I admire a man who always takes the lead when something needs to be done (Item 14: MANI).

Third person: It is admirable for a man to take the lead when something needs to be done (Item 23: MANI-II).

Gender comparative items were also avoided so as to ensure the independence of statements exploring masculinity. Their necessary exclusion indicated the need to abandon "antifemininity" as one of the five core dimensions included within the conceptual model of the MANI and to alter individual items that were gender comparative. The example below demonstrates a revision of the latter kind as well as its emphasis on progressive masculinity ideology:

Gender comparative and traditional ideology: It is pointless to try and have a serious discussion with a woman (Item 40: MANI).

Gender exclusive and progressive ideology: Men should feel embarrassed to talk about sex with their friends (Item 34: MANI-II).

Here, the original item was gender comparative in its implicit mention of both men and women. The revised item attempted to assess participant support for the concept of male objectification of sex rather than male dismissal of female intellect and, hence, their subtle sexual objectification of females. To accommodate nonconventional attitudes, the revised item also reflected a progressive masculinity ideology. 
Lastly, Thompson and Pleck (1995) also indicate the importance of including items that are prescriptive in their exploration of dominant attitudes, as well as descriptive in their appraisal of traditional behavior:

Prescriptive: Men should be calm in difficult situations (Item 40: MANI-II). Descriptive: Men who cry in public are weak (Item 3: MANI-II).

In sum, a theoretical review of the MANI revealed the need to revise the instrument's name so as to stress its multidimensionality. Wide-ranging changes to the original measure were also undertaken with reference to Thompson, Pleck, and Ferrera's (1992) seminal discussion about measures of masculinity ideology.

\section{The Male Role Norms Inventory}

The MRNI (Levant et al. 1992) seeks to assess attitudes toward traditional notions of Western masculinity. The initial measure included fifty-eight items to which participants were asked to indicate their agreement or disagreement along a 7-point Likert-type response format. These were predominantly prescriptive and included both normative and nontraditional statements.

It was argued that a number of traditional masculine norms operate in any given society. Individuals are said to vary in the extent to which they endorse these depending on their contextual positioning. As such, the authors' stressed the importance of construct multidimensionality in which "there is no single standard for masculinity nor is there an unvarying masculinity ideology. Rather, because masculinity is a social construction, ideals of manhood may differ for people” (Levant and Fischer 1996, 469). The following seven theoretical dimensions were developed to account for these norms: (1) avoidance of femininity, (2) rejection of homosexuals, (3) self-reliance, (4) aggression, (5) achievement/status, (6) attitudes toward sex, and (7) restrictive emotionality.

More recently, an additional norm, nontraditional attitudes toward masculinity, was included (Levant and Fischer 1996). Fifty-seven items now comprise the MRNI. These operationalize both the initial seven traditional norms of masculinity, as well as an eighth subscale, which assesses nontraditional participant attitudes. The total Traditional scale score excludes items from the nontraditional attitudes toward masculinity norm.

Studies report moderate to good scalar reliability, including Levant and Majors's (1997) study of 320 European American and 371 African American male and female students and Levant, Wu, and Fischer's (1996) study of 399 U.S. and 394 Chinese male and female students. The Cronbach's alpha coefficients were, respectively, Avoidance of Femininity, $=0.77,0.82$; Rejection of Homosexuals, $\quad=0.54,0.58$; Self-Reliance, $=0.54,0.51$; 
Aggression, $\quad=0.52,0.65$; Achievement/Status, $=0.67,0.69$; Attitudes toward Sex, $=0.69,0.81$; Restrictive Emotionality, $=0.71,0.81$; Nontraditional Attitudes toward Masculinity, $=0.57,0.56$; and the total Traditional scale, $\quad=0.84,0.88$. Results from the current study largely mirror these previous findings: Avoidance of Femininity, $=0.80, M=27.43, S D=$ 8.64; Rejection of Homosexuals, $\quad=0.59, M=14.60, S D=5.10$; SelfReliance, $=0.63, M=33.57, S D=6.50$; Aggression, $=0.52, M=24.24$, $S D=4.51$; Achievement $/$ Status, $=0.74, M=26.11, S D=8.01$; Attitudes towards Sex, $=0.75, M=26.01, S D=8.27$; Restrictive Emotionality, $0.75, M=24.08, S D=7.93$; Nontraditional Attitudes, $=0.56, M=43.65$, $S D=8.68$; and the total Traditional scale, $=0.93 ; M=176.05 ; S D=38.29$.

Findings concerning the MRNI's validity are mixed. Levant and Fischer (1996) comment that the measure displayed satisfactory convergent validity with the Masculine Gender Role Stress Scale (MGRSS) (Eisler and Skidmore 1987) $(r=0.52 ; p<0.001)$ as well as the Gender Role Conflict Scale-I (GRCS) (O’Neil et al. 1986) $(r=0.52 ; p<0.001)$. The MGRSS and GRCS are said to hold theoretical congruence with the MRNI and, as such, provide support for its validity. An effort to establish the MRNI's discriminant validity also proved successful. A comparison made through the use of the Personal Attributes Questionnaire (PAQ) (Spence, Helmreich, and Stapp 1974), said to measure the dissimilar theoretical concept of gender role orientation, rendered weak relationships of $r=0.06$ ( $n=97$ male students) and $r=0.08$ ( $n=220$ female students), respectively.

However, factor analytic findings question the MRNI's construct validity. A confirmatory factor analysis of the MRNI rendered three factors rather than the original seven theoretical dimensions argued to underlie the masculine construct (Levant et al. 1992):

The first consists of items from the femininity avoidance, homophobia, achievement/status, attitudes toward sex, and restrictive emotionality subscales $(=93)$. The second matched the conceptually derived self-reliance subscale $(=.62)$, and the third matched the aggression subscale $(=.48)$. (Thompson and Pleck 1995, 145)

Nevertheless, the instrument appears to offer theoretically meaningful differences in subscale scores across a variety of groups, including those defined through gender, age, marital status, and geographical location (Levant and Fischer 1996; Thompson, Pleck, and Ferrera 1992; Thompson and Pleck 1995). Notably, the inventory is considered useful in its inclusion of an oftenneglected sexuality dimension together with its explicit recognition of both traditional and progressive masculine ideology (Thompson and Pleck 1995). 


\section{Procedure}

Individuals were asked to participate in the study by a trained research assistant. Questionnaire completion took place either during formal lecture time or in halls of residence. Clear instructions appeared in writing on the questionnaire and were also emphasized by the assistant.

At the outset, participants were made aware of standard ethical issues. They were assured of their anonymity, confidentiality of data, and were informed of their right to withdraw at any time. Individuals receiving evenly numbered questionnaires were requested to complete MANI-II first, while

those given oddly numbered questionnaires were advised to respond to the MRNI first. It was hoped that this counter-balancing precaution would mitigate possible order effects (Neuman 1997). Finally, participants were asked to complete the questionnaire in silence.

The questionnaire comprised three sections: a demographics page, the MRNI (Levant et al. 1992), and the newly revised MANI-II. The demographics page required individuals to indicate their age, "race," marital status, and year of study. The procedure took no longer than twenty minutes in each case, and questionnaires were returned immediately after their completion. A research assistant remained present at all times.

\section{RESULTS}

It has been noted that three criteria are vital in the development of gender measures (Beere 1990). The empirical and theoretical foundation applied in the revision of the MANI has been described. This section will explore the two remaining criteria required in the development of gender measures: construct validity and reliability.

\section{Indicators of Construct Validity}

A comprehensive contextual exploration of South African masculinities enhanced the content validity of the MANI-II. The construct validity of the measure underwent assessment by means of factorial and convergent investigation.

\section{FACTORIAL VALIDITY}

An exploratory factor analysis was conducted to ascertain whether the five empirically and theoretically motivated dimensions (see Table 2) used to structure the MANI-II would similarly materialize through a priori analytic procedures in which five factors were purposively extracted through principal factor analysis (Communalities Multiple $\mathrm{R}^{2}$ ). After orthogonal varimax 
Table 3:

Three-Factor Analytic Solution

\begin{tabular}{|c|c|c|c|}
\hline Abbreviated Item Content & $\begin{array}{c}\text { Factor } \\
1\end{array}$ & $\begin{array}{l}\text { Factor } \\
2\end{array}$ & $\begin{array}{c}\text { Factor } \\
3\end{array}$ \\
\hline 1 A man should prefer rugby and soccer to art and drama. & 0.57 & & \\
\hline 2. If a man hurts himself, he should not let others see he is in pain. & 0.61 & & \\
\hline 3. Men who cry in public are weak. & 0.59 & & \\
\hline 4. Men should share their worries with other people. & 0.42 & & \\
\hline 5. To be a man, you need to be tough. & 0.52 & 0.40 & \\
\hline 6. Being called a "faggot" is one of the worst insults to a man. & & & \\
\hline 7. Men should think logically about problems. & & & \\
\hline 8 Men should appear confident even if they are not. & & & \\
\hline 9. A man should make all the final decisions in the family. & & & \\
\hline 10 Men participate in games to win. & & & \\
\hline 11. Men should be able to sleep close together in the same bed. & & & 0.49 \\
\hline 12. Men should have a job that earns them respect. & & 0.49 & \\
\hline 13. A successful man should be able to live a comfortable life. & & 0.43 & \\
\hline 14. A man deserves the respect of his family. & & 0.51 & \\
\hline 15. Men have a sex drive that needs to be satisfied. & & 0.42 & \\
\hline 16. Men should feel embarrassed if they cannot get an erection. & & & 0.40 \\
\hline 17. Men who teach children or cook should be proud. & 0.46 & & \\
\hline 18. It is not important for men to achieve orgasm during sex. & & & \\
\hline 19. It is okay for men to rely on others. & & & \\
\hline 20. If a man is frightened, he should try and not let others see it. & 0.53 & & \\
\hline 21. It is wrong for a man to be seen in a gay bar. & & & 0.65 \\
\hline 22. Men should be prepared to fight their way out of a bad situation. & 0.40 & & \\
\hline 23. A man should take the lead when something needs to be done. & & 0.42 & \\
\hline 24. A man should not feel embarrassed that he has gay friends. & & & 0.56 \\
\hline 25. A man should not worry about the future. & & & \\
\hline 26. Gay men should be beaten up. & & & 0.60 \\
\hline 27. A man's decision should not be questioned. & 0.54 & & \\
\hline 28. Men should be determined to do well. & & 0.61 & \\
\hline 29. It is important for a man to be successful in his job. & & 0.59 & \\
\hline 30. Gay men are not suited to many jobs. & & & 0.61 \\
\hline 31. Men should remain focused in difficult situations. & & 0.57 & \\
\hline 32. Men should have everyone’s respect and admiration. & & 0.47 & \\
\hline $\begin{array}{l}\text { 33. Men should be able to kiss each other without feeling ashamed. } \\
\text { 34. Men should feel embarrassed to talk about sex with friends. }\end{array}$ & & & 0.66 \\
\hline 35. Men are prepared to take risks. & & 0.45 & \\
\hline 36. It is not always a man's task to ask someone on a date. & & & \\
\hline 37. A father should be embarrassed if his son is gay. & & & 0.64 \\
\hline 38. A man should make sure that he knows about sex. & & & \\
\hline 39. A man is successful if he makes a lot of money. & & & \\
\hline 40. Men should be calm in difficult situations. & & 0.56 & \\
\hline Eigenvalue & 8.88 & 2.39 & 1.31 \\
\hline Percentage of Rotated Item Variance & 11.01 & 10.61 & 9.82 \\
\hline
\end{tabular}


factor rotation, the resultant structure, in which only items displaying a factor loading of 0.40 were retained, proved different from these guiding dimensions.

As such, principal factor analytic procedures (Communalities Multiple $\mathrm{R}^{2}$ ) were reinitiated, on this occasion restricting factor extraction to an eigenvalue criteria of 1.00 . This rendered four factors in which all items with a loading of 0.40 were retained. However, even after orthogonal varimax rotation the interpretability of these factors seemed at times "muddied.” This confusion, in addition to an appraisal of scree plot eigenvalue distribution, indicated the worth of exploring a three-factor model.

Once again, precisely the same procedures were undertaken. This attempt proved successful. Apart from item 5 ("To be a man you need to be tough"), which was found to load substantively on both factor $1(0.52)$ and factor 2 (0.40), simple structure was achieved. This item was excluded from subsequent subscale measures. Three theoretically meaningful factors emerged. These were found to account for 31.44 percent of total item variance after orthogonal varimax rotation. This solution appears in Table 3.

Items loading substantively on factor 1 were seen to reflect the belief that men should remain emotionally contained (e.g., "Men who cry in public are weak"), in which active expression preferably finds display in assertive physicality, in both the public (e.g., "Men should be prepared to fight their way out of a bad situation") and private (e.g., "A man should make all the final decisions in the family") arena. As such, this factor was best described as conveying notions surrounding the importance of masculine "toughness," and all nine items that had a substantive loading of 0.40 were included to form a sub-scale measure $(M=21.06$; $S D=6.15$; range $=9$ to 45$)$.

Factor 2 unambiguously stressed the centrality of control in men's lives. Male mastery over their lived reality appeared to encompass the need to exert control over financial (e.g., "It is important for a man to be successful in his job”), social (e.g., "Men should have everyone's respect and admiration”), and self experiences (e.g., "Men should be calm in difficult situations"). Therefore, the term control was seen to express the emphasis embedded in this factor to the greatest extent. A total of twelve items were incorporated to form a subscale measure $(M=46.53 ; S D=6.38$; range $=12$ to 60$)$ that, again, only included items with a substantive loading of 0.40 .

Eight items were found to load substantively on factor 3 at $\boldsymbol{v} 0.40$. These articulated the importance of (hetero)sexuality and its performance in dominant masculine expression. These items not only distanced real masculinity from (other) sexualities (e.g., "It is wrong for a man to be seen in a gay bar") but also tentatively stressed the value of male sexual performance (e.g., "Men should feel embarrassed if they cannot get an erection"). These items formed what was called the Sexuality subscale $(M=21.48 ; S D=6.78$; range $=8$ to 40). 
Thus, three subscale measures were formed: Toughness, Control, and Sexuality. A Total Scale score $(M=89.07 ; S D=15.96$; range $=29$ to 145) comprises the raw scores on each of the twenty-nine items included in these subscales.

\section{CONVERGENT VALIDITY}

Convergent validity attempts to assess the degree to which two supposedly similar instruments measure the same construct. As is noted above, Levant and Fischer (1996) report that the MRNI displayed satisfactory convergent validity with the GRSS (Eisler and Skidmore 1987), as well as GRCS-I (O’Neil et al. 1986). These results provide some support for its construct validity.

This suggested the worth of contrasting item response on the MANI-II with that of the MRNI. Both these instruments are said to implicitly measure masculinity ideology. A high correlation coefficient $(r=0.84 ; p<0.001)$ suggests that the MANI-II and the MRNI measure similar constructs.

Likewise, a hypothesized correlation pattern between the three subscales of the MANI-II and the seven traditional subscales of the MRNI also found support. That is to say it was anticipated that the MANI-II Toughness subscale would correlate with the MRNI Avoidance of Femininity $(r=0.68$; $p<0.001)$, Aggression $(r=0.47 ; p<0.001)$ and Restrictive Emotionality subscales $(r=0.66 ; p<0.001)$; that the MANI-II Control subscale would correlate with the MRNI Self-Reliance $(r=0.57 ; p<0.001)$ and Achievement/ Status subscales $(r=0.57 ; p<0.001)$; and that the MANI-II Sexuality subscale would correlate with the MRNI Avoidance of Femininity $(r=0.61$; $p<0.001)$, Homophobia $(r=0.67 ; p<0.001)$ and Attitudes toward Sex subscale $(r=0.61 ; p<0.001)$. An unexpectedly high correlation emerged between the MANI-II Toughness subscale and the MRNI Achievement/Status subscale $(r=0.67 ; p<0.001)$. Further discussion surrounding this point appears below.

Although not conducted in the current study, the construct validity of the MANI-II would gain further support through an assessment of its discriminant validity, thus gauging the relationship between two theoretically distinct instruments.

\section{Indicator of Reliability}

Item analysis was undertaken as a means with which to ensure scale reliability. Item means ranged from 1.69 to 4.24 (range $=1$ to 5 ) and their standard deviations from 0.67 to 1.35 . All items displayed an item-total correlation above 0.2 .

A measure of internal consistency, frequently reported in the form of coefficient alpha, is arguably the most popular and efficient means with which 
to determine scalar reliability (Beere 1990). The MANI-II was found to have excellent overall internal reliability demonstrated in a Cronbach's alpha of 0.90. In addition, all three subscales exhibited high reliability: Toughness $(=0.81)$, Control $(=0.82)$, and Sexuality $(=0.85)$. Test-retest reliability was not undertaken. This may be worthwhile in future measurement validation.

\section{CONCLUSION}

Empirical findings and theoretical debate contributed toward the revision of the MANI. Empirical revision drew on both qualitative and quantitative date. Qualitative findings suggested the need to include the entirely new dimension of sexuality other than the existing but conceptually discreet axis of homophobia. This sought to account for the large role sexuality-related issues were found to play in debate surrounding masculinity. In retrospect, a number of items were also considered to be culturally insensitive and were altered accordingly. Quantitative data indicated a number of potentially problematic items. These were reviewed and revised where necessary. Theoretical revision of the MANI revealed the need to alter the instrument's name so as to stress its multidimensionality. Wide-ranging changes were also undertaken with reference to Thompson, Pleck, and Ferrera's (1992) seminal discussion surrounding measures of masculinity ideology. These changes included the use of third-person, non-gender-comparative, progressiveversus-traditional, and descriptive-versus-prescriptive statements.

Results lend support for the construct validity and internal reliability of the MANI-II. Nevertheless, these results should be understood to contain limitations resulting from a largely unrepresentative sample.

The finding indicating that the MANI-II and the MRNI held strong convergent validity was unsurprising. Apart from the fact that both instruments explore masculinity ideology, they additionally hold common hereditary, in that the MANI drew decisively on the MRNI for its conceptual logic. In this sense, discriminant validity may have served a more constructive role. That is to say, it is possible that comparison between the MANI-II and a measure unrelated to its derivation may offer less affirming results.

The emergence of the predicted correlation pattern between the three subscales of the MANI-II and the seven traditional subscales of the MRNI lends further support for the inventory's construct validity. However, the unexpectedly high correlation between the MANI-II Toughness subscale and the MRNI Achievement/Status subscale suggests overlap in their content domain. This is evident in items such as "A man should do whatever it takes to be admired and respected" (item 3: MRNI) and "Men who teach children, or cook, should be proud" (item 17: MANI-II). These may be interpreted as 
Table 4:

Comparison between the Factor Analytic Solutions of Four Masculinity Ideology Measures

\begin{tabular}{|c|c|c|c|c|}
\hline $\begin{array}{l}\text { Measures of } \\
\text { Masculinity Ideology }\end{array}$ & $\begin{array}{c}\text { Dimension } \\
1\end{array}$ & $\begin{array}{c}\text { Dimension } \\
2\end{array}$ & $\begin{array}{c}\text { Dimension } \\
3\end{array}$ & $\begin{array}{c}\text { Dimension } \\
4\end{array}$ \\
\hline $\begin{array}{l}\text { Male Role Norms } \\
\text { Inventory (MRNI) }\end{array}$ & Aggression & Self-reliance & & $\begin{array}{l}\text { Femininity avoidance, } \\
\text { homophobia, } \\
\text { achievement/status, } \\
\text { attitudes toward sex, } \\
\text { and restrictive } \\
\text { emotionality }\end{array}$ \\
\hline $\begin{array}{c}\text { Male Role Norms } \\
\text { Scale (MRNS) }\end{array}$ & Toughness & & Status & Antifemininity \\
\hline $\begin{array}{l}\text { Male Attitude Norm } \\
\text { Inventory (MANI) }\end{array}$ & Toughness & Control & & \\
\hline $\begin{array}{l}\text { Male Role Norms } \\
\text { Inventory-II } \\
\text { (MANI-II) }\end{array}$ & Toughness & Control & & Sexuality \\
\hline
\end{tabular}

either tapping toughness or achievement/status dimensions. Future revision should address this issue.

Factorial investigation produced supportive findings concerning the MANI-II's construct validity. It is interesting to note that four separate studies attempting to determine the factor structure of the MRNI (Thompson and Pleck 1995), the MRNS (Thompson and Pleck 1986, 1987), the MANI (Luyt and Foster 2001), and the MANI-II (current study) all suggest that these instruments contain three underlining factors.

Thompson and Pleck (1995) note that a confirmatory factor analysis of the MRNI rendered three factors rather than the seven theoretical normative standards argued to underlie the masculine construct. Likewise, a triadic structure surfaced from within the MRNS in which each factor respectively stressed the centrality of (1) the status norm ( $=0.81)$, (2) the toughness norm ( $=0.74)$, and (3) the antifemininity norm $(=0.76)$ (Thompson \& Pleck, 1987). These conclusions were largely mirrored in an exploratory factor analysis of the MANI. This suggested the prominence of three factors as opposed to the five theoretically devised dimensions of masculinity. These included (1) toughness, (2) success, and (3) control (Luyt and Foster 2001). 
The current study delving into the factor structure of the MANI-II reproduced the first two of these factors but indicated the presence of a novel third, best described by the term sexuality.

Table 4 illustrates possible factor correspondence across these four measures of masculinity ideology. It seems that agreement exists in the consistent presence of a toughness dimension, although the MRNI appears to express this somewhat differently in terms of aggression (dimension 1). Strong support also transpires for the presence of a control dimension. This may alternatively be understood as self-reliance as is the case in the MRNI, although the broader notion of control may be argued to incorporate the concept of selfreliance to a greater extent (dimension 2). A dimension of success finds confirmation in two of the four instruments. It is noteworthy that in measures specifically designed to incorporate sexuality-related items-that is to say, the MRNI and the MANI-II-success fails to emerge as pivotal. The suggestion that success finds less unique influence in these measures as the result of its incorporation under more dominant dimensions, such as control in the MANI-II, holds possible explanation (dimension 3). Ambiguity appears between the remaining factors explained by the various measures. This apparent confusion may reside in the differential conceptual emphasis placed by each of the instruments. Furthermore, it is unsurprising that MANI-II failed to produce an antifemininity factor because of a purposeful attempt to avoid gender comparison (dimension 4).

Thus, reasonable similarity in factor structure appears across four instruments of masculinity ideology given differences in their conceptual framework. This provides further strong evidence in favor of the MANI-II's construct validity.

Beere (1990) argues that "there are now enough measures that new measures are not needed; rather existing measures can be improved and refined" (p. 34). But this assertion is faulty. Apart from these instruments evaluating substantially different constructs (e.g., sex-role attitudes, sex-role strain, and exaggerated sex-roles [Lenney 1991]), in addition to originating from divergent theoretical outlooks (i.e., masculine orientation versus masculine ideology [Thompson, Pleck, and Ferrera 1992]), this article questions the crosscultural relevance of any measure.

An overview of South African masculinities (see, e.g., Louw, 2001; Morrell 1998, 2001; Wardrop, 2001) alerts the informed observer to the fact that universal as well as monolithic depictions of masculinity inadequately represent the array of identities that take subtle shape within its unique sociohistorical milieu. An uneven landscape of social interaction locates each individual in preexisting, yet changing, discourses of gender. Positioning in terms of race, class, culture, age, and history contribute to a process in which masculine identity often reflects composite as well as contradictory images of what it is to be a man. 
This article has endeavored to demonstrate the process by which instruments may find contextual relevance. It does not suggest that existing instruments may not provide a valuable source of information in the construction of new measures. Rather, it implies that cross-cultural researchers should be prepared to undertake the onerous task of instrument development in each and every research undertaking so as to ensure their validity. Furthermore, a contextually driven development (or reorientation) of masculine measures affirms their multidimensionality. Thompson and Pleck (1995) note that in making active practical use of subscale variation,

one might argue that these scales do not assume a single masculinity standard. Comparing different groups or cultures on their profiles of these multidimensional instruments would empirically document the extent to which different masculinity standards are endorsed to different degrees by these groups or cultures. Others might argue, however, that these scales still assume one monolithic male role, albeit with component dimensions. (p. 135)

The contextualization of measures undercuts the criticism that "scales still assume a monolithic male role." In accounting for the contextual distinctiveness of masculine conceptualization within any instrument before its application, no such singular assumption is made. Alternately, traditional masculinity simply achieves definition at a specific moment in time and place.

Thus, an exploration into South African men offers a panoramic view of multiple masculinities in action. The country's troubled but lively political past raises the curtain to reveal a complex social stage. Male performance rests on the negotiation of intricate, ever-changing, as well as contextspecific power relations. Variability in attitudes toward traditional masculinity outlines contestation in the gender order in which hegemonic standards have been, and continue to be, open to renegotiation and change. It is argued that as a contextually sensitive multidimensional measure of masculinities, which reflects the theoretical logic of masculinity ideology, the MANI-II is able to capture difference in masculine debate in South Africa to a better extent than existing instruments.

APPENDIX

Male Attitude Norms Inventory-II

Thank you for agreeing to take part in this study. The statements listed below describe interesting situations involving men. There are no right, or wrong answers, only opinions. You are asked to express your feelings about each statement by indicating whether you - (A) Strongly Disagree, (B) Disagree, (C) have No Opinion, (D) Agree, or (E) Strongly Agree - by placing a cross in the appropriate box. 
For example:

Men should eat vegetables every day.

Strongly Disagree $\square$ Disagree $\square$ No Opinion $\square$ Agree $\square$ Strongly Agree

1. A man should prefer sports like rugby and soccer to activities like art and drama.

2. If a man hurts himself, he should try not to let others see he is in pain.

3. Men who cry in public are weak.

4. Men should share their worries with other people.*

5. To be a man, you need to be tough.

6. Being called a "faggot" is one of the worst insults to a man.

7. Men should think logically about problems.

8. Men should appear confident even if they are not.

9. A man should make all the final decisions in the family.

10. Men participate in games to win.

11. Men should be able to sleep close together in the same bed.*

12. Men should have a job that earns them respect.

13. A successful man should be able to live a comfortable life.

14. A man deserves the respect of his family.

15. Men have a sex drive that needs to be satisfied.

16. Men should feel embarrassed if they are unable to get an erection during sex.

17. Men who teach children or cook in restaurants should be proud of what they do.*

18. It is not important for men to achieve orgasm during sex.*

19. It is okay for men to rely on others.*

20. If a man is frightened, he should try and not let others see it.

21. It is wrong for a man to be seen in a gay bar.

22. Men should be prepared to physically fight their way out of a bad situation.

23. It is admirable for a man to take the lead when something needs to be done.

24. A heterosexual man should not feel embarrassed that he has gay friends.*

25. A man should not worry about the future.*

26. Gay men should be beaten up.

27. A man's decision should not be questioned.

28. Men should be determined to do well.

29. It is important for a man to be successful in his job.

30. Gay men are not suited to many jobs.

31. Men should remain focused in difficult situations.

32. Men should have the respect and admiration of everyone who knows them.

33. Men should be able to kiss each other without feeling ashamed.*

34. Men should feel embarrassed to talk about sex with their friends.*

35. Men are prepared to take risks.

36. It is not always a man's task to ask someone on a date.*

37. A father should be embarrassed if he finds out that his son is gay. 
38. A man should make sure that he knows about sex.

39. A man is successful if he makes a lot of money.

40. Men should be calm in difficult situations.

*Reverse-scored items.

\section{REFERENCES}

Archer, J. 1989. The relationship between gender-role measures: A review. British Journal of Social Psychology 28:173-84.

Beere, C. A. 1990. Gender roles: A handbook of tests and measures. New York: Greenwood.

Bem, S. L. 1974. The measurement of psychological androgyny. Journal of Clinical and Consulting Psychology 42:155-62.

Brannon, R., and S. Juni. 1984. A scale for measuring attitudes about masculinity. Psychological Documents 14:6-7.

Brittan, A. 1989. Masculinity and power. Oxford: Blackwell.

Connell, R. W. 1987. Gender and power: Society, the person and sexual politics. Stanford, CA: Stanford University Press.

Eisler, R. M., and J. R. Skidmore. 1987. Masculine gender role stress: Scale development and component factors in the appraisal of stressful situations. Behaviour Modification 11:12336.

Lenney, E. 1991. Sex roles: Measurement of masculinity, femininity, and androgyny. In Measures of personality and social psychological attitudes, edited by J. P. Robinson, P. R. Shaver, and L. S. Wrightsman. San Diego, CA: Academic Press.

Levant, R. F. 1996. The new psychology of men. Professional Psychology: Research and Practice 27:259-65.

Levant, R. F., and J. Fischer. 1996. The Male Role Norms Inventory. In Sexuality-related measures: A compendium, edited by C. M. Davis, W. H. Yarber, R. Bauserman, G. Schree, and S. L. Davis. Thousand Oaks, CA: Sage.

Levant, R. F., L. Hirsch, E. Celentano, T. Cozza, S. Hill, M. MacEachern, N. Marty, and J. Schnedeker. 1992. The male role: An investigation of contemporary norms. Journal of Mental Health Counseling 14:325-37.

Levant, R. F., and R. G. Majors. 1997. Masculinity ideology among African American and European American college women and men. Journal of Gender, Culture and Health 2:33-43.

Levant, R. F., R. Wu, and J. Fischer. 1996. Masculinity ideology: A comparison between U.S. and Chinese young men and women. Journal of Gender, Culture and Health 1:207-20.

Louw, R. 2001. Mkhumbane and new traditions of (un)African same-sex weddings. In Changing men in Southern Africa, edited by R. Morrell, 287-96. Pietermaritzburg, South Africa: University of Natal Press.

Luyt, R. 2003. Rhetorical representations of masculinities in South Africa: Moving towards a material-discursive understanding of men. Journal of Community and Applied Social Psychology 13:46-69.

Luyt, R., and D. Foster. 2001. Hegemonic masculine conceptualisation in gang culture. South African Journal of Psychology 31:1-11.

Morrell, R. 1998. Of boys and men. Journal of Southern African Studies 24:605-30. . 2001. The times of change: Men and masculinity in South Africa. In Changing men in Southern Africa, edited by R. Morrell, 3-37. Pietermaritzburg, South Africa: University of Natal Press.

Neuman, W. L. 1997. Social research methods: Qualitative and quantitative approaches. Boston: Allyn \& Bacon.

O’Neil, J. M., B. J. Helms, R. K. Gable, L. David, and L. S. Wrightsman. 1986. Gender role conflict scale: College men's fear of femininity. Sex Roles 14:335-50. 
Spence, J. T., R. L. Helmreich, and J. Stapp. 1974. The Personal Attributes Questionnaire: A measure of sex-role stereotypes and masculinity-femininity. Catalog of Selected Documents in Psychology 4:43-4.

Thompson, E. H., and J. H. Pleck. 1986. The structure of male role norms. American Behavioral Scientist 29:531-43.

. 1987. Reformulating the male role: The structure of male role norms. In Changing men: New directions in research on men and masculinity, edited by M. S. Kimmel, 25-35. London: Sage.

1995. Masculinity ideologies: A review of research instrumentation on men and masculinities. In A new psychology of men, edited by R. F. Levant and W. S. Pollack, 129-63. New York: Basic Books.

Thompson, E. H., J. H. Pleck, and D. L. Ferrera. 1992. Men and masculinities: Scales for masculinity ideology and masculinity-related constructs. Sex Roles 27:573-607.

Wardrop, J. 2001. "Simply the best”: The Soweto flying squad, professional masculinities and the rejection of machismo. In Changing men in Southern Africa, edited by R. Morrell, 25570. Pietermaritzburg, South Africa: University of Natal Press.

Wetherell, M., and C. Griffin. 1991. Feminist psychology and the study of men and masculinity. Part I: Assumptions and perspectives. Feminism and Psychology 1:361-91.

Russell Luyt has recently moved from the University of Cape Town and now works in the Department of Social Psychology at the London School of Economics. He has a longstanding interest in gender studies and, in particular, the critical exploration of masculinities. His published work includes discussion surrounding the rhetorical representation of masculinities and exploration into masculinities and gang culture. He is currently researching the reproduction of masculinities in the South African gender order. 